\title{
Evaluation of the Frequency of Risk Factors in Venous Thromboembolic Patients Admitted to Ekbatan and Farshchian Hospitals in Hamadan from 2012 to 2017
}

\author{
Farnaz Fariba ${ }^{1}$, Nasrin Jiryaee ${ }^{2, *}$ (i) , Chonoor Neshatyar ${ }^{3}$, Masoud Tarbiat ${ }^{4}$
}

${ }^{I}$ Associate Professor, Department of Cardiology, School of Medicine, Hamadan University of Medical Sciences, Hamadan, Iran

${ }^{2}$ Assistant Professor, Department of Social Medicine, School of Medicine, Hamadan University of Medical Sciences, Hamadan, Iran

${ }^{3}$ Medical Student, Hamadan University of Medical Sciences, Hamadan, Iran

${ }^{4}$ Assistant Professor, Department of Anesthesia, School of Medicine, Hamadan University of Medical Sciences, Hamadan, Iran

* Corresponding Author: Nasrin Jiryaee, Department of Social Medicine, School of Medicine, Hamadan University of Medical Sciences, Hamadan, Iran.Email: n_jiryaee@yahoo.com

Received: 02.12.2018 Accepted: 13.04.2019

\section{How to Cite this Article:} Fariba F, Jiryaee N, Neshatyar $\mathrm{Ch}$, Tarbiat M. Evaluation of the Frequency of Risk Factors in Venous Thromboembolic Patients Admitted to Ekbatan and Farshchian Hospitals in Hamadan from 2012 to 2017. Avicenna J Clin Med. 2019; 26(1): 60-66. DOI: $10.29252 /$ ajcm.26.1.60

\section{Abstract}

Background and Objective: Venous thromboembolism is one of the major causes of mortality worldwide. Various environmental and genetic factors are known as risk factors for this disease. Therefore, this study aimed to investigate the frequency of risk factors in patients with venous thromboembolism admitted to Ekbatan and Farshchian hospitals in Hamadan from 2012 to 2017.

Materials and Methods: This cross-sectional descriptive study investigated all patients with venous thromboembolism who had medical records regarding risk factors of venous thromboembolism using census sampling method. The obtained data were analyzed in SPSS software (Version 21).

Results: According to the results, out of 226 patients under study, 116 $(51.3 \%)$ ones were male. Moreover, $103(45.6 \%), 76(33.6 \%)$, and 47 (20.8\%) patients had deep venous thrombosis, pulmonary embolism, and severe lung embolism with deep venous thrombosis, respectively. The mean \pm SD age of patients was $59.15 \pm 19.85$ years. Moreover, the most frequent risk factors associated with venous thromboembolism include the history of hypertension (37.2\%), recent hospitalization (29.6\%), cardiovascular problems $(27.5 \%)$, history of recent surgery $(16.8 \%)$, history of intravenous thromboembolism $(8.8 \% 16 \%)$, history of smoking $(16.8 \%)$, statin use $(15.5 \%)$, history of hyperlipidemia $(13.7 \%)$, and catheterization $(13.7 \%)$.

Conclusion: Venous thromboembolism is a multifactorial disease in which some risk factors contribute to the increased risk of it directly and indirectly.

Keywords: Embolism, Risk Factors, Venous Thrombosis 


\title{
بررسى فراوانى ريسكفاكتورها در بيماران مبتلا به ترومبو آمبولى وريدى مر اجعه كننده

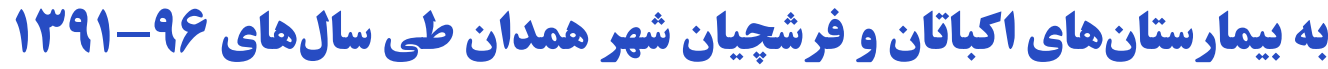

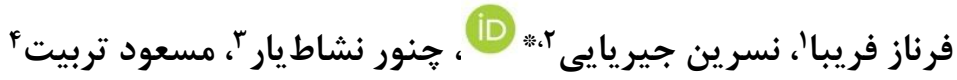 \\ ' انشيار، كروه قلب و عروق، دانشكده يزشكى، دانشكاه علوم يزشكى همدان، همدان، ايران

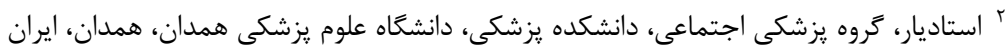

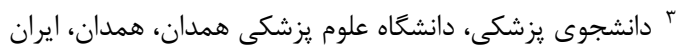

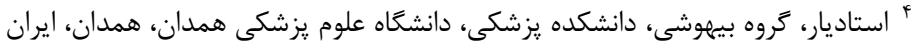
* *ويسنده مسئول: نسرين جيريايى، گروه يزشكى اجتماعى، دانشكده يزشكى، دانشگاه علوم يزشكى همدان، همدان، ايران. ايميل: n_jiryaee@yahoo.com

\begin{tabular}{|c|c|}
\hline 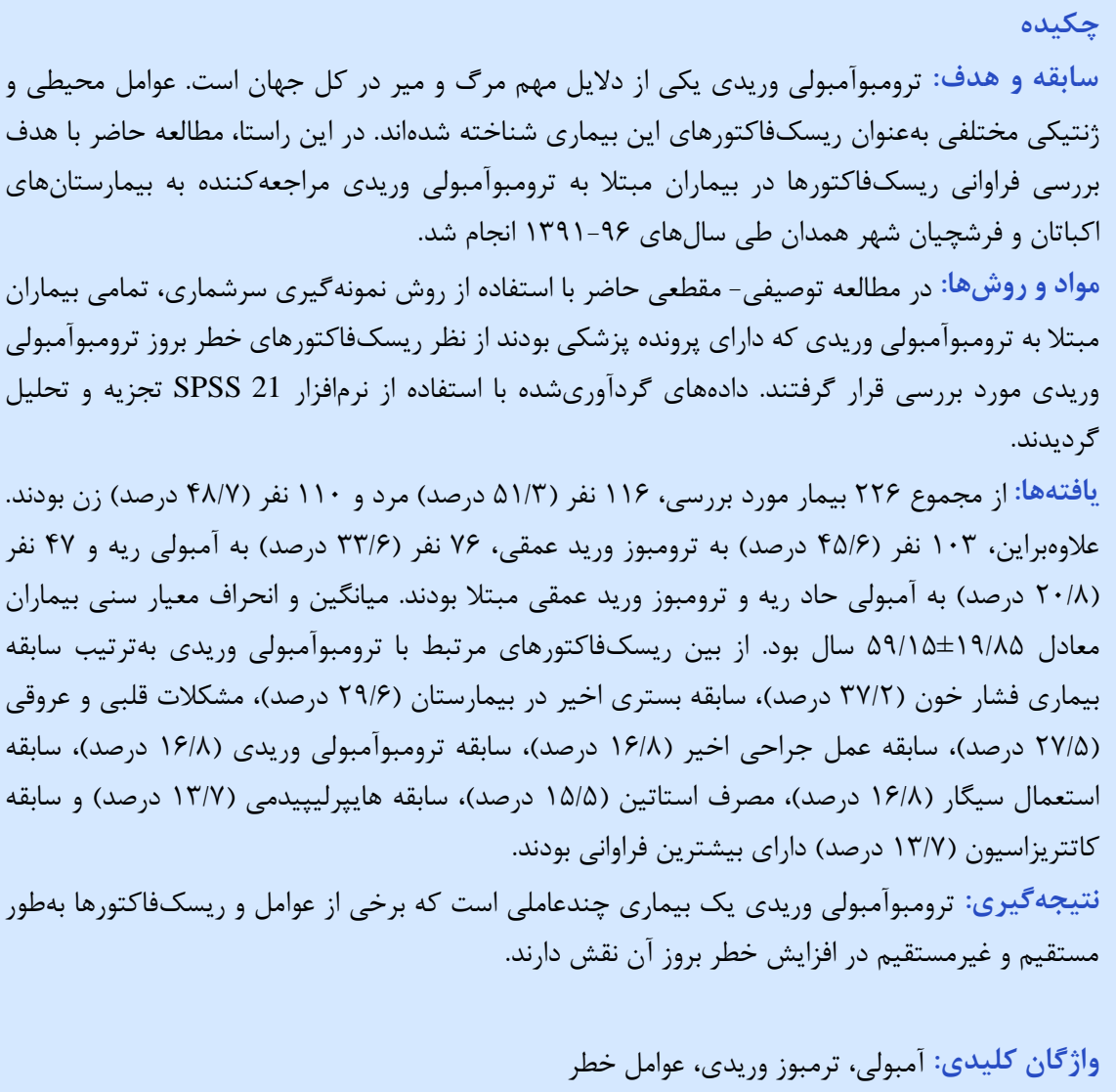 & 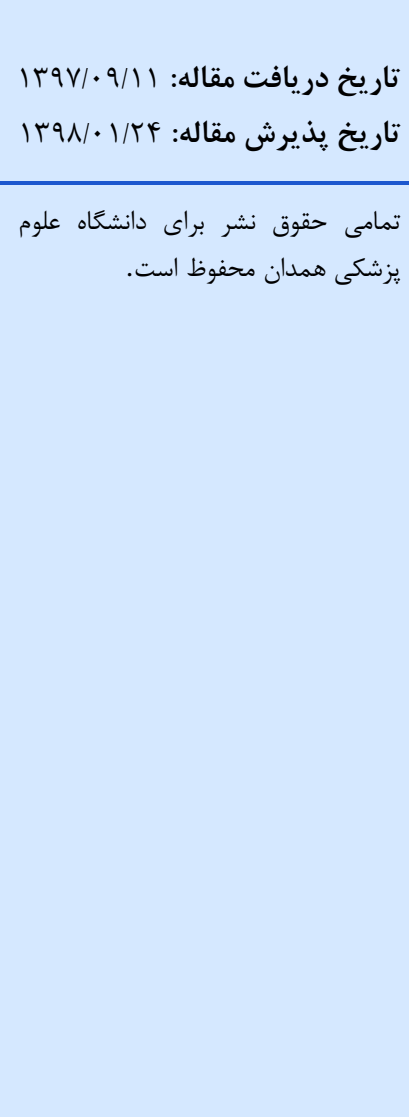 \\
\hline
\end{tabular}

مقدمه

متحده آمريكا رخ مىدهد [Y]]. حدود • • درصد از موارد VTE

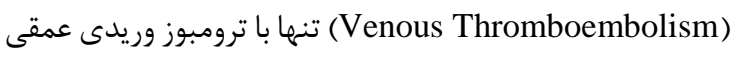

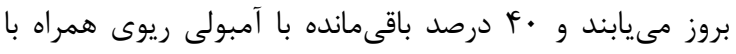

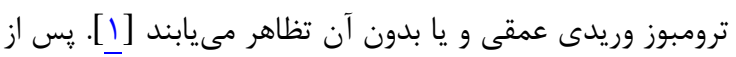

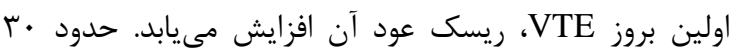

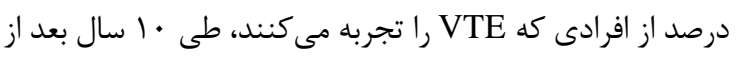

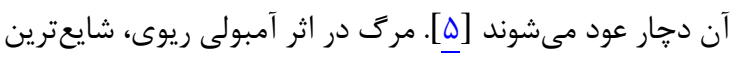

ترومبوآمبولى وريدى كه شامل ترومبوز وريدى عمقى و

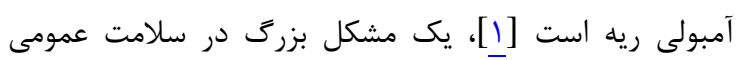

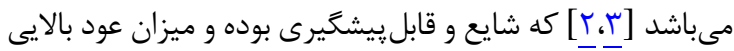

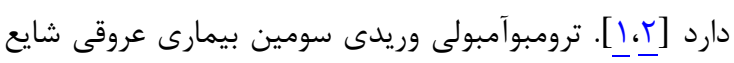

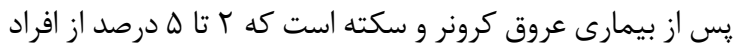

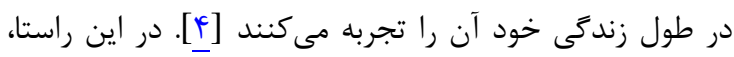

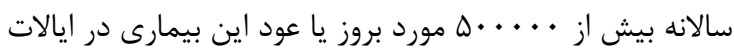




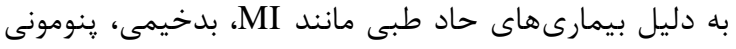

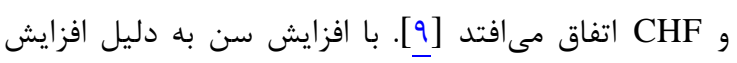

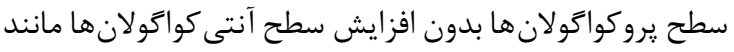

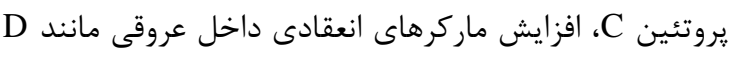

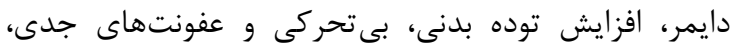

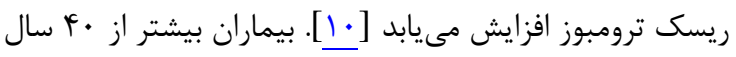

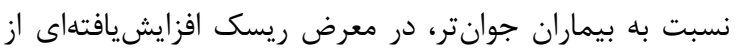

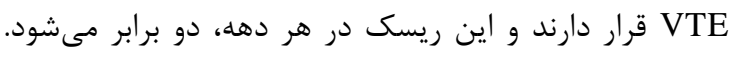

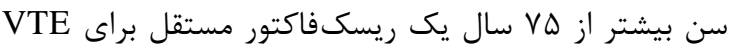

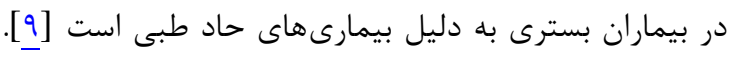

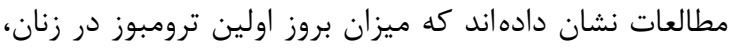

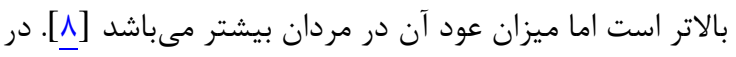

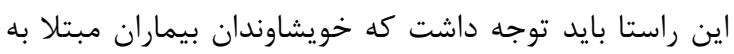

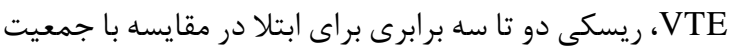

عمومى دارند [11].

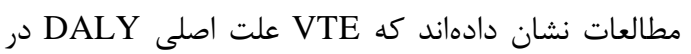

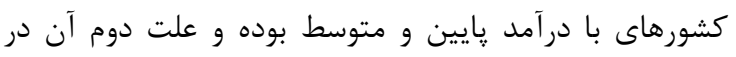

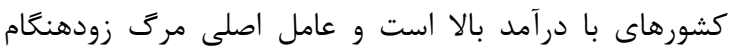
مىباشد. بايد توجه داشت كه آكاهى عمومى مردم عاد در در مورد ترومبوز كم بوده و دانش يايهاى بيشتر مردم در مورد علائم و

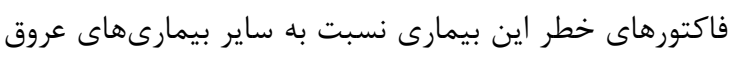

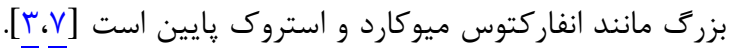

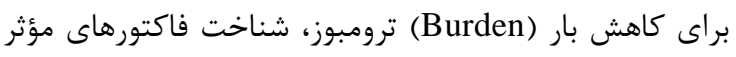
در وقوع آن امرى ضرورى مى باشد و شناخت اين فاكتورها منجر

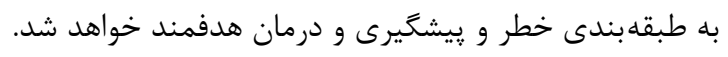

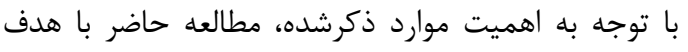

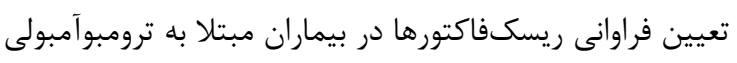

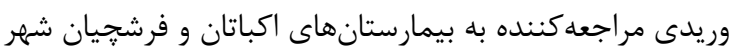

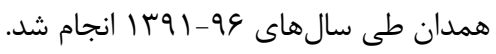

\section{مواد و روشها}

در مطالعه توصيفى- مقطعى حاضر ابتدا با استفاده از

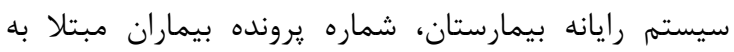

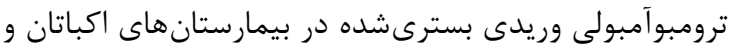

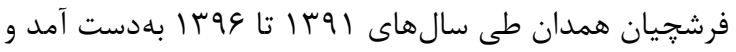
با مراجعه به يرونده يزشكى بيماران، دادهان هاى مورد نياز شامل:

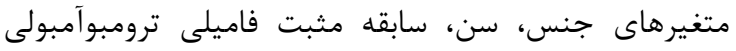
ريوى، سابقه مصرف سيگار، سابقه شكستخى و تروما، سابقه سنه

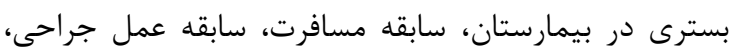

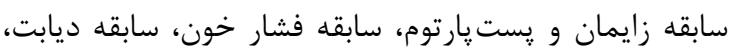

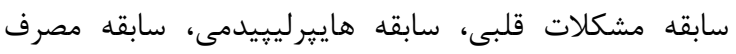
OCP/HRT سابقه فاكتور ه ليدن مثبت و سابقه كاتتريزاسيون از يرونده

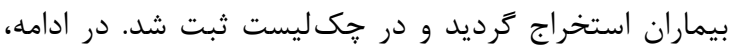

دليل قابل ييشگيرى مرگ بيمارستانى مىباشد [ع]. لازم به ذكر

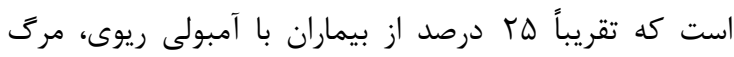

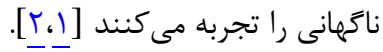
حوادث VTE ممكن است با فاكتورهاى ييشكويى كننده همراه

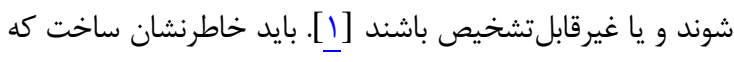

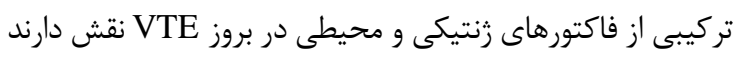

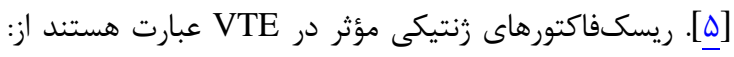
موتاسيون فاكتور V ليدن، موتاسيون زن ترومبين و كمبود يروتئين Provoking يا S C هستند (مانند سرطان، جراحى، تروما، (Predisposing Factors)

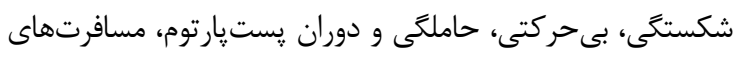

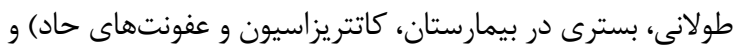
برخى (Idiopathic) Nonprovoking) هستند (مانند سن، جنس، نزاد، Body Mass Index) BMI)، جاقى، (ماني Hormone ) HRT (Combined Oral Contraceptive) Replacement Therapy

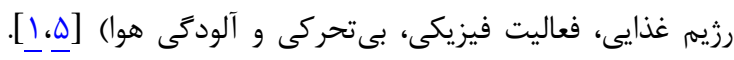

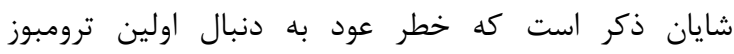
Unprovoked

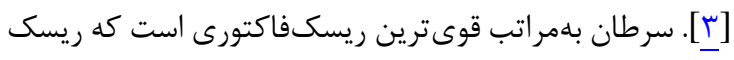

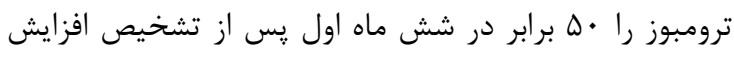

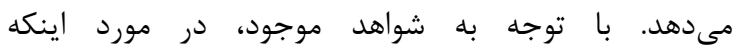

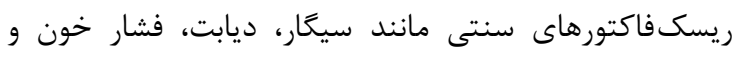

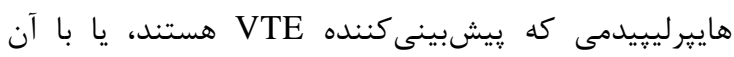

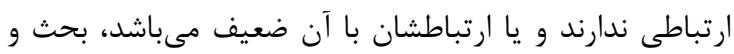

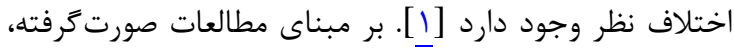

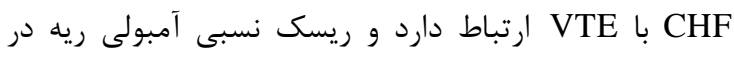
بيماران CHF / CHF در مقايسه با بيمارانى كه

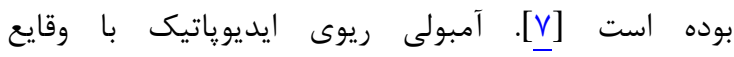

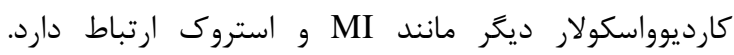

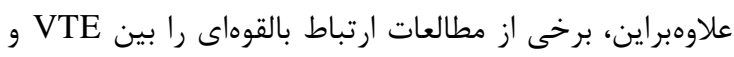

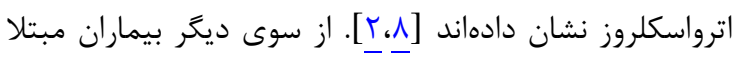

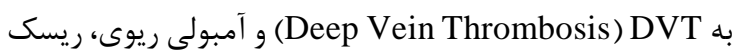
افزايشيافته قابلملاحظهاى براى سكته قلبى و استروى در

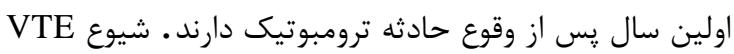

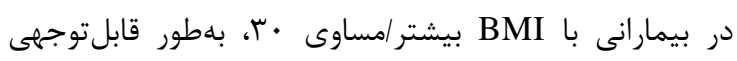

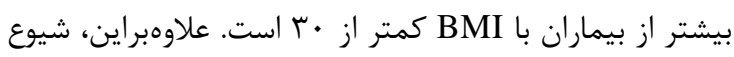
VTE

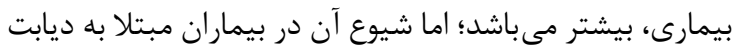

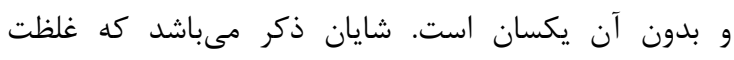

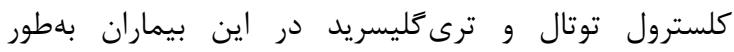

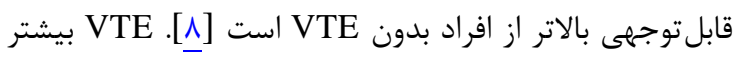

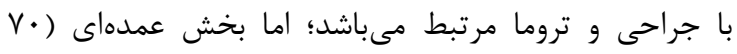

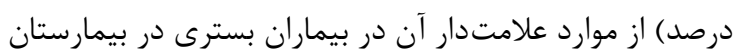


سال با كمينه و بيشينه 11 و • إل سال بود. بايد عنوان نمود كه

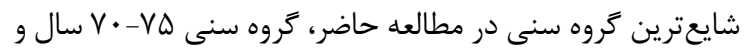

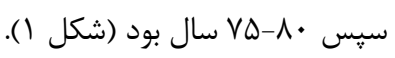

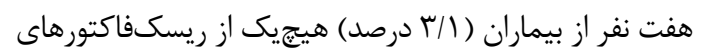

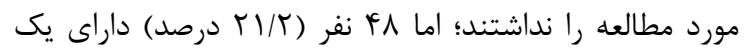

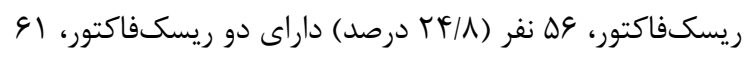

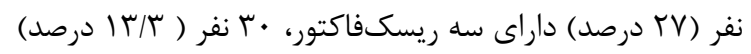

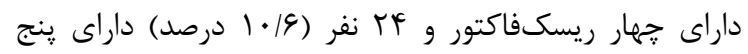
ريسكفاكتور و بالاتر بودند.

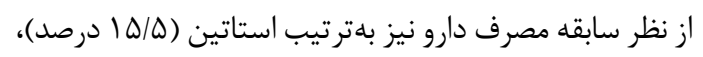

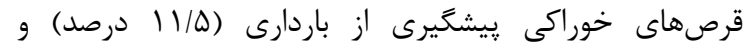

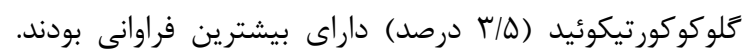

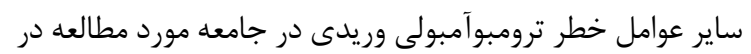
جدول ا قابلمشاهده مىباشد.
دادهها با استفاده از نرمافزار 21 SPSS تجزيه و تحليل

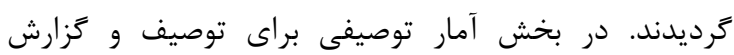

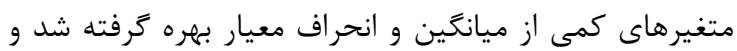

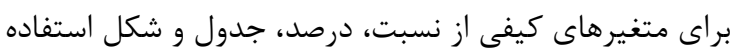
كرديد. - مري.

\section{بافْته هـا}

در مطالعه حاضر צrr بيمار واجد معيارهاى ورود به مطالعه

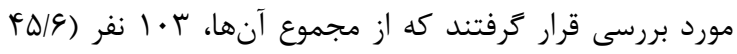

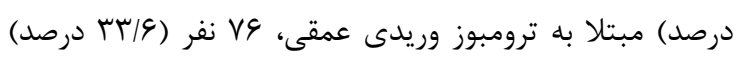

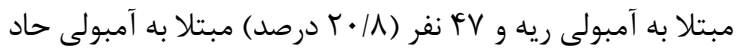

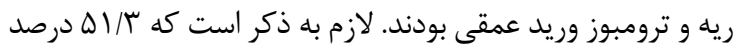

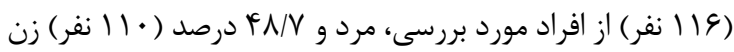

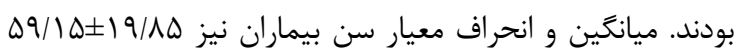

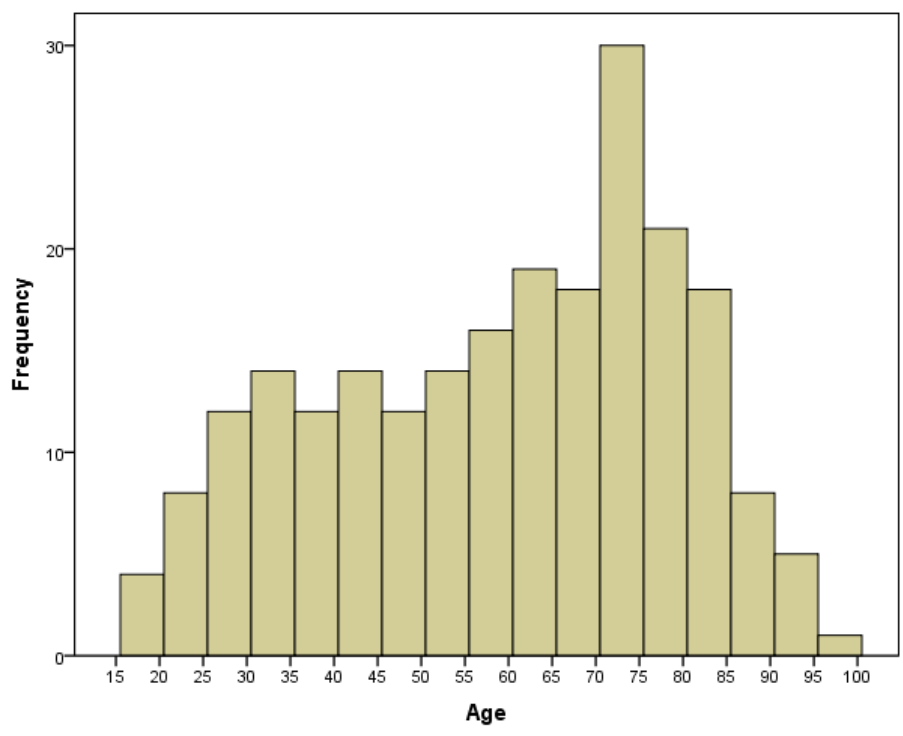

شكل ا: فراوانى ترومبوآمبولى وريدى به تفكيك گروههاى سنى جامعه مورد مطالعه

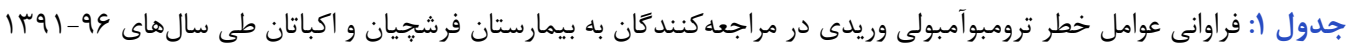

\begin{tabular}{|c|c|c|c|}
\hline 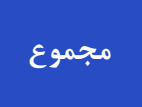 & تعداد (درصداكتور ندارد) & تعداد (درصفاكتور دارد) & \\
\hline$(1 \cdots)$ r & $(\wedge F / \Delta) 191$ & $(1 \Delta / \Delta) r \Delta$ & سابقه مصرف استاتين \\
\hline$(1 \cdots)$ TrG & $(\Lambda \Lambda / \Delta) \Gamma_{\cdots}$ & $(1) / \Delta) T \varepsilon$ & OCP \\
\hline$(1 \cdots)$ TYG & $(१ ९ / Q) \Upsilon \backslash \wedge$ & $(\Gamma / \Delta) \wedge$ & سابقه مصرف گَلوكوكور تيكوئيد \\
\hline (1) TrG & $(99 / 1)$ TYF & $(\cdot 19) r$ & 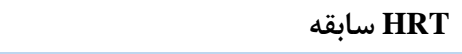 \\
\hline (1..) TrE & $(G T / \Lambda) I F T$ & $(r V / T) \wedge F$ & فشار خون \\
\hline 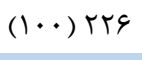 & $(V T) 190$ & $(Y Y) 91$ & سابقه مشكلات قلبى و عروقى \\
\hline$(1 \cdot)$ TrE & $(\wedge \& / \Gamma) \backslash 9 \Delta$ & $(I r / V) K_{1}$ & هيير لييبدمى \\
\hline$(1 \cdots)$ TrE & $(\wedge \& / \vee) 198$ & $(I \mu / \mu) \mu \cdot$ & ديابت \\
\hline$(1 \cdots)$ TrG & $(\mathrm{AN} / 1) 199$ & $(11 / 9) T V$ & سابقه شكستغى و تروما \\
\hline$(1 \cdot)$ TYG & $(q F / V) Y / F$ & $(\Delta / \mu) \mid r$ & سرطان \\
\hline (1..) זT\& & $(V \cdot / q) F \Delta q$ & $(Y q / 9) \& V$ & سابقه بسترىشدن در بيمارستان اخير \\
\hline$(1 \cdots)$ TKG & $(\Lambda \mu / r) \backslash \Lambda \Lambda$ & $(|\&| \Lambda)$ rA & سابقه عمل جراحى اخير \\
\hline
\end{tabular}




\begin{tabular}{|c|c|c|c|}
\hline & & & ادامه جدول ا. \\
\hline (1) (1) TrG & $(\Lambda r / r) \backslash \Lambda \Lambda$ & $(|\varepsilon| \Lambda) \Upsilon \Lambda$ & سابقه قبلى ترومبو آمبولى وريدى \\
\hline$(1 \cdots)$ TYG & $(\Lambda \Gamma / r) \backslash \Lambda \Lambda$ & 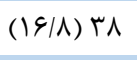 & استعمال سيعار \\
\hline$(1 \cdots)$ Trg & $(\Lambda 9 / \pi) 190$ & $(I r / V) M_{1}$ & سابقه كاتتريزاسيون \\
\hline (1) TrG & $(\Lambda \Lambda / 1) 199$ & $(1) / 9) r V$ & سابقه شكستغى و تروما \\
\hline$(1 \cdots)$ TrE & $(9) / r) r \cdot 4$ & $(\Lambda / \Lambda) Y \cdot$ & سابقه مسافرت اخير همراه با بى تحركى طولانى \\
\hline$(1 \cdots)$ TTE & $(9 \Delta / 9) 1 \% \varphi$ & $(\mathcal{F} / \mathcal{f}) 1$ & سابقه يست پيار توم اخير \\
\hline (1) TrE & $(q r / f) r \mid l$ & $(\varepsilon / 9) 10$ & 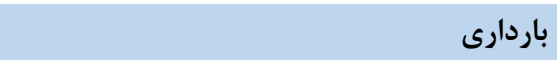 \\
\hline$(1 \cdots)$ TrG & $(9 \Lambda / \cdot r) Y I V$ & $(\% / 91) 9$ & كمبود يروتئين C/S \\
\hline$(1 \cdots)$ TTE & $(9 \Lambda / 4)$ TTt & $(1 / \wedge){ }^{f}$ & فاكتور ه ليدن مثبت \\
\hline$(1 \cdots)$ TrG & (9N/V) TrM & $(1 / r) r$ & سابقه فاميلى مثبت ترومبو آمبولى وريدى \\
\hline
\end{tabular}

درصد از مبتلايان سابقه مصرف OCP داشتند [ها]. در اين مطالعه درصد فراوانى ترومبوآمبولى وريدى در افرادى كه سابقه دمانه

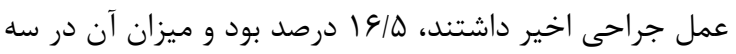

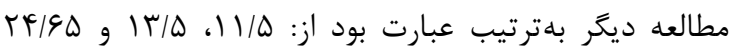

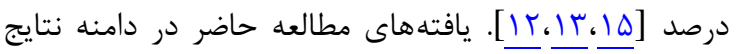

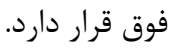
علاوهبراين، در مطاله حاضر وارد ب/9 درصد از بيماران مبتلا به

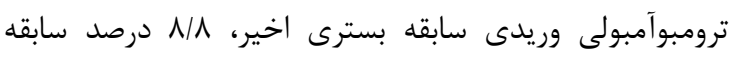
مسافرت و بى تحركى طولانى مدت، ساه

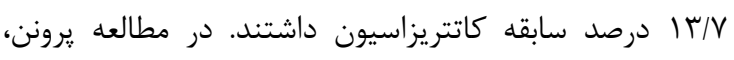

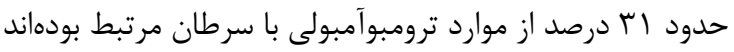

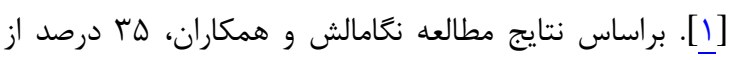

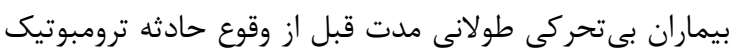

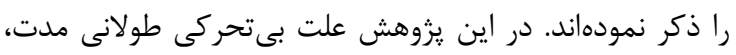

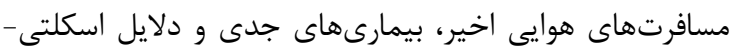

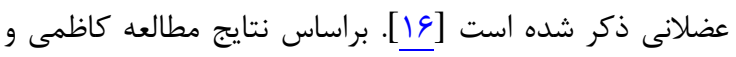

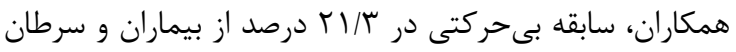

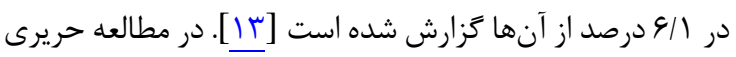

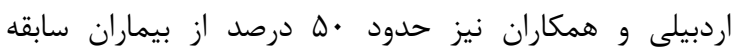

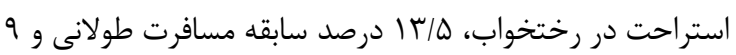

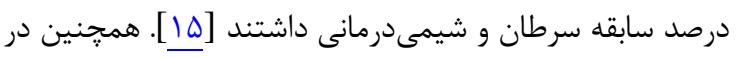

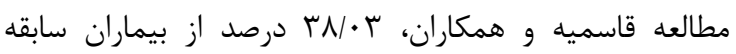

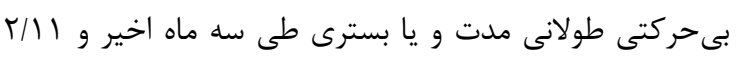
درصد سابقه سرطان داشتند [1 II]

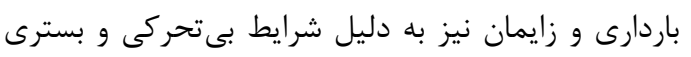

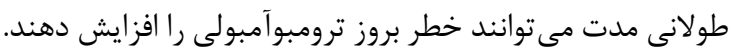

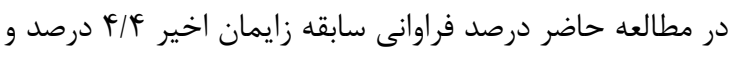

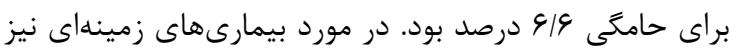

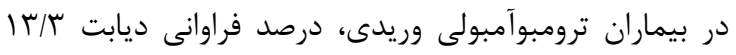

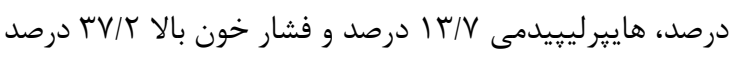

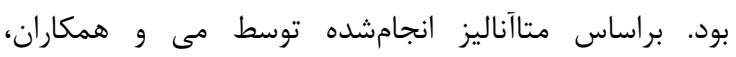

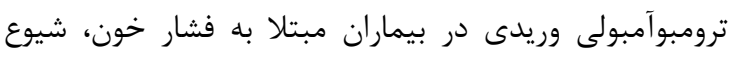
بالاترى نسبت به بيماران بدون فشار خون داشت؛ ديد اما شيوع آن
نتايج نشاندهنده آن هستند كه از نظر بيمارى بلهترتيب

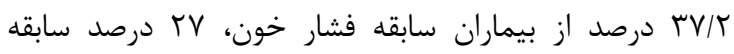

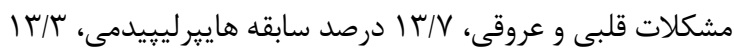

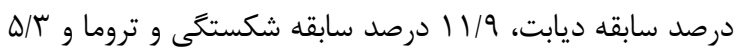
درصد سابقه سرطان داشتهاند.

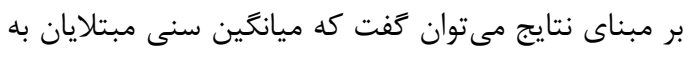
ترومبوآمبولى ريوى (19/4.

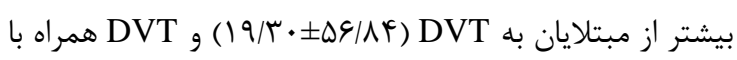

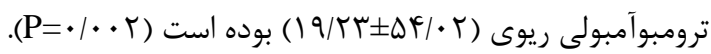

بج

در مطالعه حاضر \& \& ع درصد از بيماران مبتلا به آمبولى و

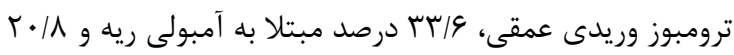

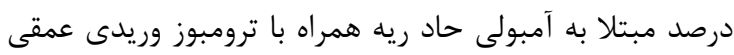

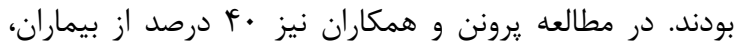

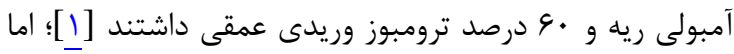

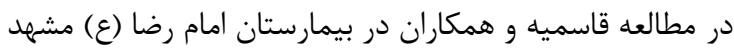

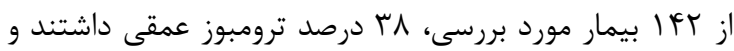
سايرين داراى ترومبوز ريوى بودند [1 إ].

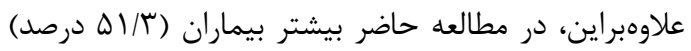

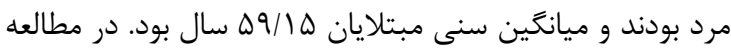

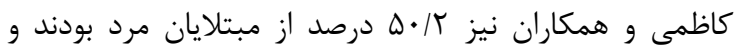

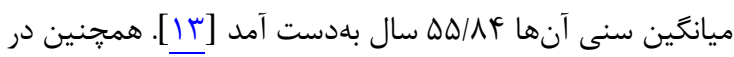

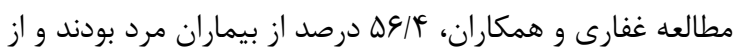

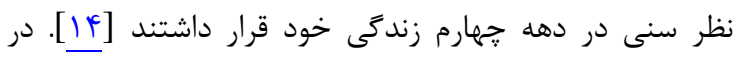

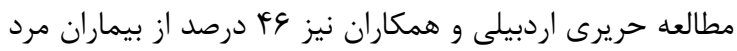

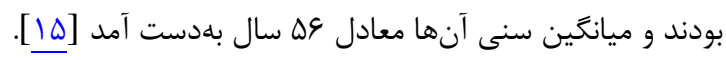

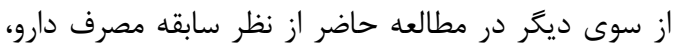

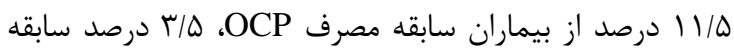

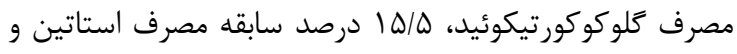
q درصد سابقه HRT داشتند. براساس نتايج مطالعه يرونن و و همكاران، HRT و استاتين از ريسكفاكتورهاى ترومبوآمبولى دئ دئي

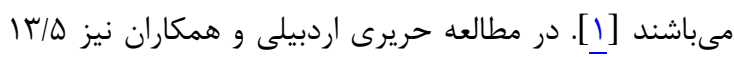


بروز ترومبوآمبولى توصيه مىشود كه در گروههاى در معرض

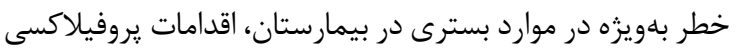
صورت گيرد [11] با اين وجود، حتى اكر تمامى بيماران در معرض خطر بسترى لئر

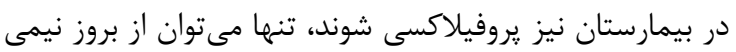

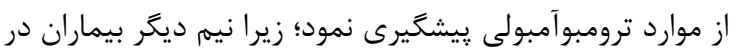
بيمارستان بسترى نيستند و حتى ممكن است علائم و نشانههاى

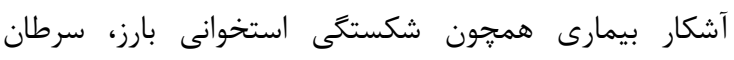

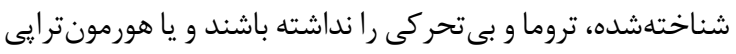

نَخردند [ب]

\section{نتيجه تيرى}

ترومبوآمبولى وريدى يك بيمارى مولتىفاكتوريال است كه

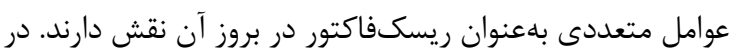

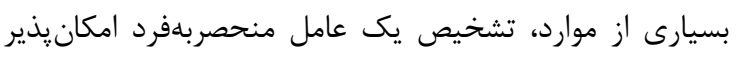

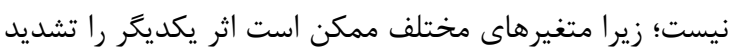

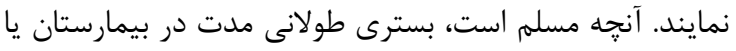

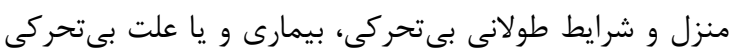

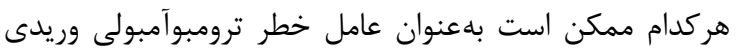

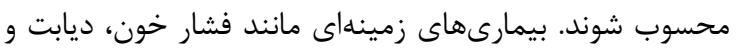

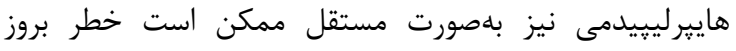

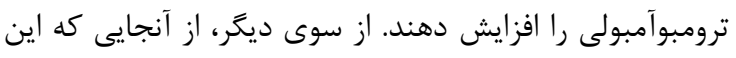

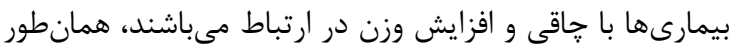

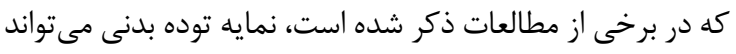

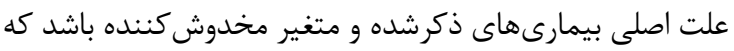

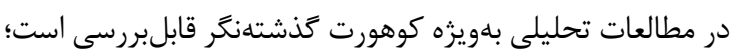
اگر جه نقش عوامل زنتيك نيز نبايد ناديده كرفته شود.

\section{تشكر و قلروداذى ماضى}

مقاله حاضر بركرفته از يايان نامه دوره دكترى عمومى يزشكى

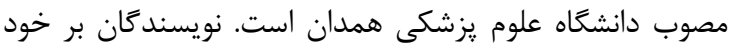
لازم مى دانند از بيماران شركت كننده در اين مطالعه كه صميمانه

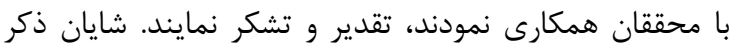

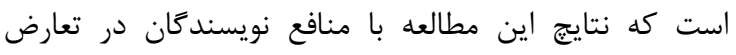
نمى باشد.

\section{REFERENCES}

1. Puurunen MK, Gona PN, Larson MG, Murabito JM, Magnani JW, O'Donnell CJ. Epidemiology of venous thromboembolism in the Framingham Heart Study. Thromb Res. 2016;145:27-33. PMID: 27442716 DOI: 10.1016/j.thromres.2016.06.033

2. Cohoon KP, Ashrani AA, Crusan DJ, Petterson TM, Bailey $\mathrm{KR}$, Heit JA. Is infection an independent risk factor for venous thromboembolism? A population-based, case-control study. Am J Med. 2018;131(3):307-16. PMID: 28987552 DOI: $10.1016 /$ j.amjmed.2017.09.015

3. Heit JA, Crusan DJ, Ashrani AA, Petterson TM, Bailey KR. Effect of near-universal hospitalization-based prophylaxis on annual number of venous thromboembolism events in the US.
در بيماران مبتلا به ديابت و بدون آن يكسان بود. علاوهبراين،

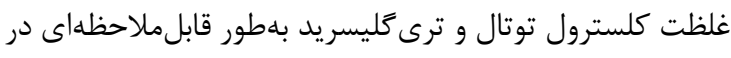

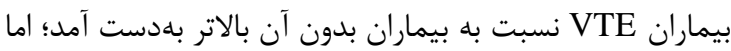

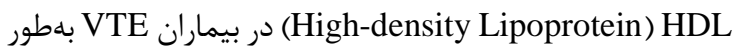

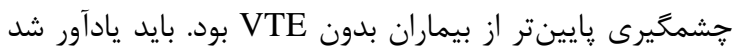

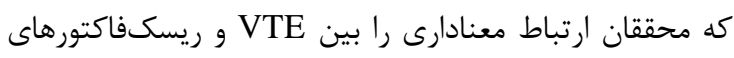
آترواسكلروزيس گزارش نمودهاند [IV]

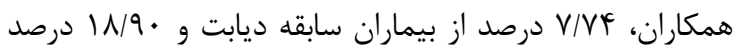

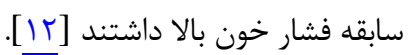

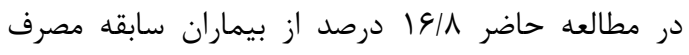

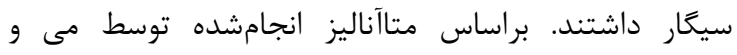

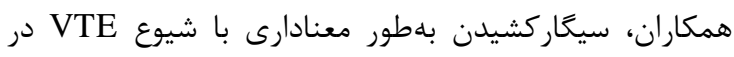

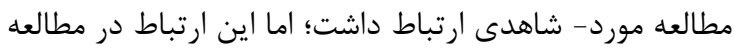

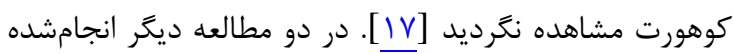

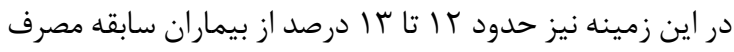

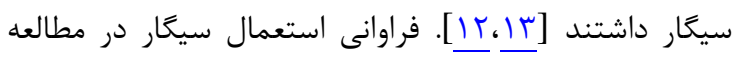

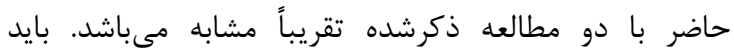

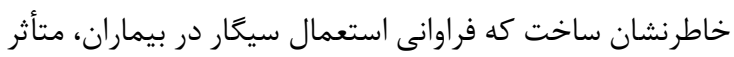

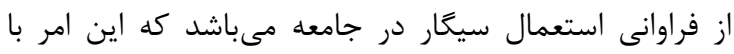

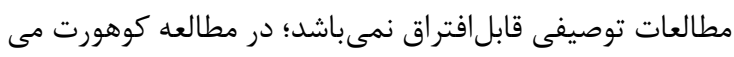

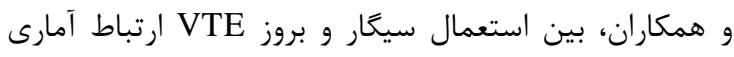
معنادارى مشاهده نغرديد [IV]

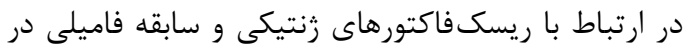

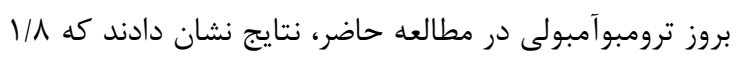

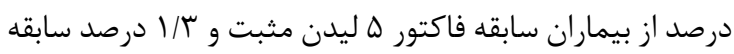

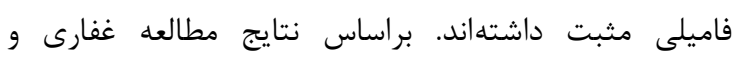

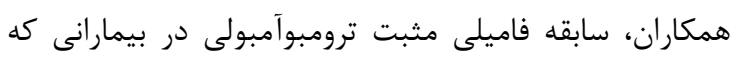

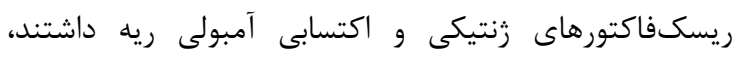

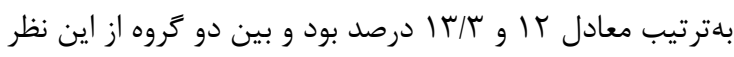

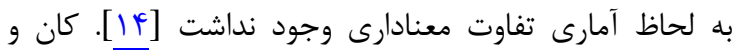
همكاران نيز در مطالعه مورد- شاهدى خود با حجم نمونه نسبتاً

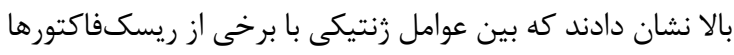

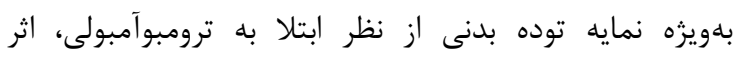

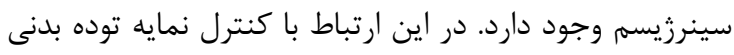

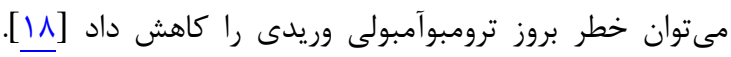

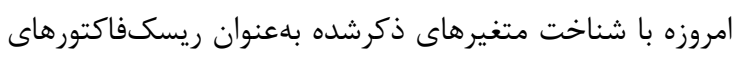

Blood. 2017;130(2):109-14. PMID: 28483763 DOI: 10.1182/ blood-2016-12-758995

4. Farzamnia H, Rabiei K, Sadeghi M, Roghani F. The predictive factors of recurrent deep vein thrombosis. ARYA Atheroscler. 2011;7(3):123-8. PMID: 22577459

5. Heit JA. Epidemiology of venous thromboembolism. Nature Rev Cardiol. 2015;12(8):464-74. PMID: 26076949 DOI: 10.1038/nrcardio.2015.83

6. ChendrasekharA, Aleti S. Venous thromboembolism risk assessments on trauma patients has suboptimal interobserver reliability among inexperienced clinicians (fourth-year medical students). Int J Gen Med. 2018;11:225-31. PMID: 
29950883 DOI: 10.2147/IJGM.S162025

7. Heit JA, Silverstein MD, Mohr DN, Petterson TM, O'Fallon WM, Melton LJ 3rd. Predictors of survival after deep vein thrombosis and pulmonary embolism: a population-based, cohort study. Arch Int Med. 1999;159(5):445-53. PMID: 10074952

8. Crous-Bou M, Harrington LB, Kabrhel C. Environmental and genetic risk factors associated with venous thromboembolism. Semin Thromb Hemost. 2016;42(8):80820. PMID: 27764878 DOI: $10.1055 / \mathrm{s}-0036-1592333$

9. Goldhaber SZ. Risk factors for venous thromboembolism. $J$ Am Coll Cardiol. 2010;56(1):1-7. PMID: 20620709 DOI: 10.1016/j.jacc.2010.01.057

10. Rosendal FR. Causes of venous thrombosis. Thromb J. 2016;14(1):24. PMID: 27766050 DOI: 10.1186/s12959-0160108-y

11. Geerts WH, Code KI, Jay RM, Chen E, Szalai JP. A prospective study of venous thromboembolism after major trauma. $N$ Engl J Med. 1994;331(24):1601-6. PMID: 7969340 DOI: $10.1056 /$ NEJM199412153312401

12. Ghasemieh J, Rezaeetalab F. Evaluation of the clinical features, diagnostic procedures and mortality of acute pulmonary thromboembolism pulmonary and Ttuberculosis Research Center, Mashhad of Medical Sciences University. Med J Mashhad Univ Med Sci. 2008;51(2):115-20. [Persian]

13. Kazemi T, Qasemi M, Taghavi SM. Epidemiologic study of patients with DVT in Birjand Vali-Easr hospital-(20092014). J Birjand Univ Med Sci. 2016;23(1):1-6. [Persian]

14. Ghaffary MR, Ansarin K, Sakhinia E, Khoramifar AR. Thrombophilia and biological fat of pulmonary embolism. Razi J Med Sci. 2013;20(108):70-7. [Persian]

15. Aghazade M, Hariri Ardabili A, Peirzade AM. The prevalence of blood groups in patients with deep vein thrombosis and pulmonary embolism. [Doctoral Dissertation]. Ardabil, Iran: Ardabil University of Medical Sciences; 2012. [Persian]

16. Nagamalesh UM, Prakash VS, Naidu KC, Sarthak S, Hegde AV, Abhinay T. Acute pulmonary thromboembolism: Epidemiology, predictors, and long-term outcome. A single center experience. Indian Heart J. 2017;69(2):160-4. PMID: 28460762 DOI: $10.1016 /$ j.ihj.2016.08.010

17. Mi Y, Yan S, Lu Y, Liang Y, Li C. Venous thromboembolism has the same risk factors as atherosclerosis: a PRISMAcompliant systemic review and meta-analysis. Medicine. 2016;95(32):e4495. PMID: 27512866 DOI: 10.1097/MD. 0000000000004495

18. Kahn SR, Lim W, Dunn AS, Cushman M, Dentali F, Akl EA, et al. Prevention of VTE in nonsurgical patients: antithrombotic therapy and prevention of thrombosis: American College of Chest Physicians evidence-based clinical practice guidelines. Chest. 2012;141(2):e195Se226S. PMID: 22315261 DOI: 10.1378/chest.11-2296 